\title{
UNA APROXIMACION A LOS DETERMINANTES SOCIOECONOMICOS DE LA MORTALIDAD INFANTIL Y DE NIÑEZ EN BOLIVIA: USO DE METODOS INDIRECTOS DE CALCULO DE MORTALIDAD Y ANALISIS BIVARIADO
}

\section{Pamela Córdova y Marina Nicolaeva}

\section{RESUMEN}

A pesar de las importantes mejoras en los resultados de salud infantil y de niñez durante el Siglo XXI en América Latina, las tasas de mortalidad infantil y de niñez permanecen inaceptablemente altas en Bolivia encontrándose entre las más elevadas la región, solo por debajo de Haití, dirigiéndose a una deficiente salud infantil y de niñez. Estos resultados requieren de evidencia científica sobre la mejor manera de hacer frente a sus determinantes. Este estudio aproxima, teóricamente, mediante el marco teórico propuesto por Mosley-Chen y Sastry, los determinantes de la mortalidad infantil y de niñez en Bolivia enfocados en características individuales, del hogar y contextual. Además se examina de manera preliminar los niveles y magnitudes de la mortalidad mediante el uso de métodos directos e indirectos de estimación mediante la técnica propuesta por la versión Trussel y la versión Palloni-Heligman del Método de Brass y se realiza un análisis bivariado que da cuenta de relaciones existentes entre la mortalidad infantil y de niñez y las variables a nivel del hogar, individual y contextual relacionado con las políticas públicas.

Palabras clave: Mortalidad, Analisis Bivariado, Política Pública. 